\title{
Debating Core Conceptual and Measurement Issues About Police Legitimacy-Editor's Introduction
}

\author{
Jianhong Liu ${ }^{1}$
}

Received: 16 October 2019 / Accepted: 21 October 2019/Published online: 10 November 2019

(C) Springer Nature B.V. 2019

This special issue on police legitimacy assembles a group of articles that debate the core conceptual and measurement issues about police legitimacy by authors from different backgrounds. These issues are very important given the growing expansion of the literature around the concept of police legitimacy. We organize this issue to provide the platform for authors to express views and critiques around both conceptual and methodological issues of police legitimacy.

Legitimacy is quite important for legal authorities, as people obey the law and cooperate only when they consider the legal authorities to be legitimate. The study of police legitimacy is largely directed by Tylor's work. Legitimacy is defined as "a psychological property of an authority, institution, or social arrangement that leads those connected to it to believe that it is appropriate, proper, and just" (Tyler 2006, p. 375). Following Tyler's approach, large number of previous studies regarded the obligation to obey the police as the measurement of police legitimacy, and they identified procedural justice, distributive justice, effectiveness, and lawfulness as the four major possible sources of police legitimacy. However, Tankebe (2013) initiated a new approach by arguing that procedural justice, distributive justice, effectiveness, and lawfulness were constituent components of police legitimacy but not potential sources. This round of debate was stimulated by a paper published in Issue 13 of the Asian Journal of Criminology titled "Police Legitimacy and Citizen Cooperation in China: Testing an Alternative Model" by Sun et al. (2018), in which the authors tested the new model for police legitimacy proposed by Tankebe (2013) instead of the most frequently tested framework-Tylor's process-based policing model. In that paper, by second-order confirmatory factor analysis and structural equation modeling analysis of a sample from a city in Southern China, Sun et al. supported Tankebe's work that police legitimacy actually comprised the four aspects: procedural justice, distributive justice, effectiveness, and lawfulness, which influenced people's obligation to obey the police and cooperate with the police. This result stimulated a wave of debate around the conceptual and measurement issues of police legitimacy. As the research of Sun et al. was conducted in China, a society with a totally different

Jianhong Liu

jliu@um.edu.mo

1 Department of Sociology, University of Macau, Room 3002, Social Science Building E21, Avenida da Universidade, Taipa, Macau, China 
tradition and social context, it might be a chance for researchers to enrich the discussion on the concept of police legitimacy and largely expand our understanding and the literature.

This special issue contains the first article titled "Blurring the Distinction Between Empirical and Normative Legitimacy? A Methodological Commentary on 'Police Legitimacy and Citizen Cooperation in China"' by Jackson and Bradford (2019) which is aimed at making a methodological commentary to the paper of Sun et al. (2018). This commentary indicated that Sun and his colleagues blurred the distinction between empirical and normative legitimacy at the conceptual aspect and overly interpreted the statistical analysis result at the methodological aspect, which meant that confirmatory factor analysis could not decide the four aspects (procedural justice, distributive justice, effectiveness, and lawfulness) as the source or the constituent components of police legitimacy. Jackson and Bradford also raised the confirmatory analysis results of data from 30 countries to show that the same finding was easy to be found so that it was an "erroneous" approach. They thought that legitimacy should be considered as something distinct from police fairness, effectiveness, and lawfulness so that it was possible to distinguish the most influential predictor and the effect of other variables was also easier to be assessed.

Cao and Graham (2019) immediately made a responsive commentary to Jackson and Bradford's article in their paper "The Measurement of Legitimacy: A Rush to Judgment?" which was the second paper of this issue. They pointed out that although the warning against confirmatory factor analysis as the adjudication tool was adequate, Jackson and Bradford actually raised more foundational problems about how to examine theories in varied contexts and about the interrogation of operationalizing key constructs within criminology. Cao and Graham thought that Sun et al.'s analysis strategy and process were in accordance with the principles of scientific study, and Jackson and Bradford's critiques were somewhat overstated. The author also proposed that both are imposing an a priori definition to test legitimacy and discovering variations of legitimacy from the bottom-up should be considered.

In the third paper of this issue titled "Clarifying the Contours of the Police Legitimacy Measurement Debate: A Response to Cao and Graham”, Trinkner (2019) firstly reviewed the theoretical measurement strategies of both Tyler (2006) and Tankebe (2013) and then outlined Sun et al.'s (2018) work and Jackson and Bradford's (2019) subsequent critique. The author then pointed out that many of Cao and Graham's critiques were based on mischaracterizations of Jackson and Bradford's arguments and the central methodological critique was also not adequately responded. After the detailed analysis, Trinkner (2019) summarized that this debate was not about which approach should be adopted regarding Tylor's or Tankebe's conceptualization, but about the use of confirmatory factor analysis in the empirical research about legitimacy and the possible issues that might arise if the mistaken strategy was widely adopted.

Except for the above three papers, this issue also comprises two replies, respectively, from Sun et al. (2019) and Cao (2019). In response to Jackson and Bradford (2019), Sun et al. (2019) argued that the issues that they labeled the latent factor as "legitimacy" in the CFA model and proposed the four factors as components of legitimacy were actually theoretical rather than methodological. They thought legitimacy could be directly embedded in procedural and distributive justice, effectiveness, and lawfulness and the approach of Tankebe (2013) might be useful in an authoritarian society such as China. The author also thought that Jackson and Bradford did not report their theoretical rationale and had some misrepresentations of their previous study. Responding to the reviewers' comments made on the paper in the issue by Cao and Graham (2019), Cao (2019) addressed the three major points of 
their previous paper and indicated some misstatements they thought the reviewers had made. The author also emphasized the importance of diversity in interpretation and measurement of a theory.

I believe these debates on a key issue contribute to the literature of police legitimacy very meaningfully and decide to bring this topic issue to our audience for broader evaluation and debates.

\section{Compliance with Ethical Standards}

Conflict of Interest The author declares that there are no conflicts of interest.

\section{References}

Cao, L. (2019). Response to criticism-police legitimacy: beyond the entrenched niches of expertise. Asian Journal of Criminology., 14(4).

Cao, L., \& Graham, A. (2019). The measurement of legitimacy: a rush to judgment? Asian Journal of Criminology., 14(4).

Jackson, J., \& Bradford, B. (2019). Blurring the distinction between empirical and normative legitimacy? A methodological commentary on 'police legitimacy and citizen cooperation in China'. Asian Journal of Criminology First online 1 June 2019.

Sun, Y. I., Li, L., Wu, Y., \& Hu, R. (2018). Police legitimacy and citizen cooperation in China: testing an alternative model. Asian Journal of Criminology., 13, 275-291.

Sun, Y. I., Wu, Y., \& Li, L. (2019). Response to criticism-understanding the conceptual and measurement models of legitimacy. Asian Journal of Criminology., 14(4).

Tankebe, J. (2013). Viewing things differently: the dimensions of public perceptions of legitimacy. Criminology, $51,103-135$.

Trinkner, R. (2019). Clarifying the contours of the police legitimacy measurement debate: a response to Cao and Graham. Asian Journal of Criminology, 14(4).

Tyler, T. R. (2006). Psychological perspectives on legitimacy and legitimation. Annual Review of Psychology, 57, $375-400$.

Publisher's Note Springer Nature remains neutral with regard to jurisdictional claims in published maps and institutional affiliations. 